\title{
Development of Japanese Version of Smartphone Dependence Scale
}

\author{
Satoko Ezoe' ${ }^{*}$, Tadayuki Iida ${ }^{2}$, Ken Inoue ${ }^{3}$, Masahiro Toda ${ }^{4}$ \\ ${ }^{1}$ Health Service Center Izumo, Shimane University, Shimane, Japan \\ ${ }^{2}$ Department of Physical Therapy, Faculty of Health and Welfare, Prefectural University of Hiroshima, \\ Hiroshima, Japan \\ ${ }^{3}$ Department of Public Health, Gunma University Graduate School of Medicine, Gunma, Japan \\ ${ }^{4}$ Graduate School of Human Life Sciences, Notre Dame Seishin University, Okayama, Japan \\ Email: "satoezoe@med.shimane-u.ac.jp
}

Received 27 July 2016; accepted 19 August 2016; published 22 August 2016

Copyright (C) 2016 by authors and Scientific Research Publishing Inc.

This work is licensed under the Creative Commons Attribution International License (CC BY).

http://creativecommons.org/licenses/by/4.0/

(c) (i) Open Access

\section{Abstract}

We designed a Japanese version of the Smartphone Dependence Scale (J-SDS) for university students, and assessed its validity and reliability. For development of this scale, we initially selected 43 preliminary items based on previous studies of Internet and mobile phone dependence. Each response was scored using a Likert scale $(0,1,2,3)$, with higher scores indicating greater dependence. After administering the preliminary scale to 149 university students, the final 29 items were selected according to exploratory factor analysis. The final scale consisted of 5 factors: 1 ) craving and withdrawal, 2) overuse and tolerance, 3) virtual life orientation, 4) disturbance of concentration in class, and 5) physical symptoms. Reliability coefficient (Cronbach's alpha) values for the 5 factors and total J-SDS were $0.87,0.87,0.76,0.77,0.69$, and 0.92 , respectively. We then summed the Likert scores for each item to provide a quantitative overall smartphone dependence score, with higher scores indicating greater dependence. The J-SDS score became significantly higher with longer hours of smartphone use $(p<0.001)$. Our results suggest that the J-SDS is a reliable and valid scale for screening university students who may be at risk of developing smartphone dependence.

\section{Keywords}

Smartphone Dependence, Japanese Version of Smartphone Dependence Scale, Internet Addiction, Reliability, Validity, Factor Analysis, University Students

\footnotetext{
${ }^{*}$ Corresponding author.
} 


\section{Introduction}

The smartphone has rapidly developed over recent years and its use has become widespread an established part of daily life in many countries. According to the Ministry of Internal Affairs and Communications of Japan, the penetration rate of mobile phone use was $94.6 \%$ in 2014, with smartphones comprising $64.2 \%$ of those devices [1]. While this information and communication technology resource is very convenient and popular, various social issues have arisen in association with its use, including changes in interpersonal relationships, interference with school or work, physical health-related problems including pain in the wrists or back of the neck, sleep disturbance, excessive use, and even dependence (addiction). As various applications have been developed for use with smartphones allowing the Internet to become more accessible, patterns of dependence have been routinely reported [2].

Because of its mobility and Internet capabilities, a smartphone can induce characteristics of dependence in users, such as overuse, tolerance, problems with withdrawal, difficulty with performing study or work, and cyber life orientation. Previous studies conducted in South Korea of university students have indicated associations of smartphone dependence with mental health, campus life, personal relations, self-control, and life stress [3] [4]. Adolescents may be at higher risk for exhibiting problems seen with the use of smartphones as compared to adults, because younger generations typically use smartphones as the primary tool to access the Internet [2] [5].

Smartphone dependence especially among adolescents has recently become a very important problem in Japan. However, few valid or reliable scales have been developed to measure such dependence, thus there is an urgent need for a smartphone dependence scale that can be used for Japanese students.

In the present study, we referred to previous studies of Internet and mobile phone dependence to design a Japanese smartphone dependence scale for university students. We then, administered a questionnaire concerning smartphone use to 149 university students in Japan, and investigated the construction, as well as reliability and validity of the scale.

\section{Subjects and Methods}

\subsection{Subjects}

We recruited 169 healthy university students twenty and over from the Faculty of Medicine of Shimane University and the Faculty of Health and Welfare of the Prefectural University of Hiroshima in Japan from December 2015 to January 2016. They were from first-year to fifth-year students whose majors were medicine, nursing, or physical therapy. After receiving approval for the study protocol from the review boards of the institutions and informed consent from each participant, the subjects were asked to answer a set of self-reporting questionnaires designed to evaluate smartphone use and dependence. Answers from 149 of the respondents (32 males and 117 females; mean age $22.3 \pm 2.1$ and $21.1 \pm 1.9$ years, respectively) who regularly used a smartphone and properly completed all of the questionnaire items were statistically analyzed.

\subsection{Demographic Information}

Items pertaining to subject personal information, and the extent and nature of their smartphone use were included in the questionnaire.

\subsection{Smartphone Dependence Scale Items}

As it has been hypothesized that smartphone dependence has many aspects that are similar to those of Internet addiction, we referred to the Internet addiction criteria [6] when developing smartphone dependence scale. Based on previously developed scales and research findings [2] [6]-[13], items that were considered to theoretically and empirically represent the characteristics of smartphone dependence were selected to comprise the present tool, termed the Japanese version of the Smartphone Dependence Scale (J-SDS). The preliminary scale consisted of 43 items, and each was scored on a 4 -point Likert scale $(0=$ strongly disagree, $1=$ disagree, $2=$ agree, 3 = strongly agree), with higher scores indicating greater dependence.

\subsection{Statistical Analysis}

The final items of the J-SDS were selected according to exploratory factor analysis using a principal component 
factoring estimation of varimax rotation. A scree plot of ordered eigenvalues was used to determine the appropriate number of factors extracted. A factor loading value $>0.40$ was used to determine the items for each factor. The reliability coefficient (Cronbach's alpha) values of the factors extracted and total J-SDS were calculated for internal consistency determination. Likert scores for each item of the final J-SDS were summed to provide a quantitative overall smartphone dependence score, with higher scores indicating greater dependence. A Kolmogorov-Smirnov test was used to determine whether the J-SDS scores were normally distributed. To examine concurrent validity of the J-SDS, we used Spearman's correlation coefficient to examine the relationships of hours of smartphone use during weekdays and holidays with J-SDS score, and one-way analysis of variance and post hoc analyses to examine the relationships of hours of smartphone use from 10:00 p.m. to 4:00 a.m. and while in bed with J-SDS score. All analyses were performed using IBM SPSS Statistics version 19 [14].

\section{Results}

The final 29 items of the J-SDS were selected according to exploratory factor analysis. Factor loading for the 29 variables after rotation of commonfactors extracted is shown in Table 1. Five factors were extracted for these variables, i.e., craving and withdrawal (10 items: first 10 listed in Table 1), overuse and tolerance (8 items: numbers 11 - 18), virtual life orientation (6 items: numbers 19 - 24), disturbance of concentration in class (2 items: numbers 25 and 26), and physical symptoms (3 items: numbers 27 - 29).

The reliability coefficient (Cronbach's alpha) values of the 5 factors extracted and the total J-SDS were 0.87, $0.87,0.76,0.77,0.69$, and 0.92 , respectively.

Kolmogorov-Smirnov test results indicated that the scores of the J-SDS were normally distributed ( $\mathrm{p}=0.72$ ). Mean scores for the J-SDS and hours of smartphone use during weekdays and holidays, as well as Spearman's correlation coefficient between J-SDS score and hours of smartphone use are shown in Table 2. Hours of smartphone use during weekdays as well as holidays were significantly positively related to J-SDS score. Figure 1 shows the relationship of hours of smartphone use from 10 p.m. to 4 a.m. with J-SDS score. That score showed a significant increase in association with hours of smartphone use from 10 p.m. to 4 a.m. $(\mathrm{F}=8.44, \mathrm{p}<$ 0.001). Furthermore, the J-SDS score also significantly increased as the hours of smartphone use while in bed increased $(\mathrm{F}=8.95, \mathrm{p}<0.001)$ (Figure 2).

\section{Discussion}

We developed the J-SDS on the basis of previous studies and used exploratory factor analysis with university students as subjects to establish its 5-factor structure, i.e.,: 1) craving and withdrawal, 2) overuse and tolerance, 3) virtual life orientation, 4) disturbance of concentration in class, and 5) physical symptoms. The factor "craving and withdrawal" includes the feeling of anxiety, impatience, and pain without a smartphone and constantly having one's smartphone in mind even when not using it, while "overuse and tolerance" refers to long and uncontrollable periods of use of one's smartphone, trying to control one's smartphone use but failing to do so, and spending an increasing amount of time using the smartphone to achieve the same level of satisfaction as previously experienced. The factor "virtual life orientation" includes the feeling that communication with one's smartphone is more enjoyable and intimate than relationships with real-life friends or family, "disturbance of concentration in class" refers to having a difficult time concentrating in clas due to smartphone use, and "physical symptoms" include headache, stiff shoulders and pain in the wrists or at the back of the neck due to excessive smartphone use. These 5 factors were partially consistent with previously reported findings regarding factors related to Internet addiction, which were listed as unpleasant feelings when off-line (withdrawal), excessive time spent on Internet-related activities (overuse and virtual life orientation), increasing tolerance to the effects of being online, and denial of associated problematic behaviors [6]. Therefore, we consider that the J-SDS has construct validity.

The values for Cronbach's alpha coefficient for the present 5 factors extracted and total J-SDS were 0.87, $0.87,0.76,0.77,0.69$, and 0.92 , respectively. Although the value for the factor "physical symptoms" was not so high, the total J-SDS exhibited good internal consistency.

In the present study, hours of smartphone use during weekdays as well as holidays showed a significant positive relationship to J-SDS score. Furthermore, the J-SDS score was significantly increased when the hours of smartphone use from 10 p.m. to 4 a.m. and when those in bed increased. These results indicated the concurrent validity of the J-SDS. 
Table 1. Factor loading for 29 variables of smartphone dependence for common factors (FC1, FC2, FC3, FC4, FC5) ${ }^{\mathrm{a}}$ in 149 university students extracted by factor analysis.

\begin{tabular}{|c|c|c|c|c|c|}
\hline Smartphone dependence & FC1 & FC2 & FC3 & FC4 & FC5 \\
\hline $\begin{array}{l}\text { I feel anxious when I forget to take my smartphone } \\
\text { with me or when I am not able to use my smartphone }\end{array}$ & $\underline{0.595}$ & 0.282 & 0.120 & 0.320 & 0.053 \\
\hline $\begin{array}{l}\text { I feel impatient and restless when my smartphone is } \\
\text { unavailable }\end{array}$ & $\underline{0.567}$ & 0.112 & 0.366 & 0.382 & 0.151 \\
\hline I feel pleasant or excited while using a smartphone & $\underline{0.411}$ & 0.289 & 0.275 & 0.048 & -0.045 \\
\hline $\begin{array}{l}\text { My smartphone is on my mind even when I am not } \\
\text { using it }\end{array}$ & $\underline{0.484}$ & 0.254 & 0.312 & 0.119 & 0.185 \\
\hline $\begin{array}{l}\text { I would not be able to tolerate not having a } \\
\text { smartphone }\end{array}$ & $\underline{0.687}$ & 0.333 & 0.063 & 0.058 & 0.014 \\
\hline $\begin{array}{l}\text { I feel anxious when I have not prepared my charging } \\
\text { pack or battery for my smartphone }\end{array}$ & $\underline{0.483}$ & 0.057 & 0.192 & 0.085 & 0.101 \\
\hline I use my smartphone while walking & $\underline{0.465}$ & 0.156 & -0.001 & 0.026 & 0.195 \\
\hline I am able to get rid of stress by using a smartphone & $\underline{0.483}$ & 0.313 & 0.254 & -0.009 & -0.055 \\
\hline $\begin{array}{l}\text { I don't really want to go to places where smartphone } \\
\text { signals are weak }\end{array}$ & $\underline{0.637}$ & 0.076 & 0.202 & 0.250 & 0.033 \\
\hline $\begin{array}{l}\text { It would be painful if I was not allowed to use a } \\
\text { smartphone }\end{array}$ & $\underline{0.692}$ & 0.380 & 0.123 & 0.061 & -0.013 \\
\hline My smartphone use has increased & 0.029 & $\underline{0.625}$ & 0.042 & 0.057 & 0.145 \\
\hline I have missed planned work due to smartphone use & 0.250 & $\underline{0.518}$ & 0.225 & 0.299 & 0.110 \\
\hline I involuntarily touch my smartphone & 0.305 & $\underline{0.579}$ & -0.032 & 0.075 & 0.070 \\
\hline $\begin{array}{l}\text { I have reduced my study, work or hobby time due to } \\
\text { smartphone use }\end{array}$ & 0.213 & $\underline{0.611}$ & 0.194 & 0.214 & 0.250 \\
\hline $\begin{array}{l}\text { I use my smartphone for longer periods than I } \\
\text { hadintended }\end{array}$ & 0.270 & $\underline{0.584}$ & -0.003 & 0.056 & 0.107 \\
\hline $\begin{array}{l}\text { I need to spend an increasing amount of time using my } \\
\text { smartphone to achieve the same satisfaction as before }\end{array}$ & 0.161 & $\underline{0.615}$ & 0.358 & 0.068 & 0.092 \\
\hline $\begin{array}{l}\text { I have tried to shorten my smartphone use time, but } \\
\text { always fail }\end{array}$ & 0.392 & $\underline{0.609}$ & 0.179 & 0.180 & 0.069 \\
\hline $\begin{array}{l}\text { Spending a lot of time on my smartphone has become } \\
\text { a habit }\end{array}$ & 0.339 & $\underline{0.523}$ & 0.287 & 0.054 & 0.018 \\
\hline $\begin{array}{l}\text { I feel that my communication with my smartphone is } \\
\text { more enjoyable than conversations with my real-life } \\
\text { people }\end{array}$ & 0.117 & 0.203 & $\underline{0.642}$ & 0.031 & 0.116 \\
\hline $\begin{array}{l}\text { It is difficult to communicate with other people } \\
\text { without using a smartphone for that }\end{array}$ & 0.259 & 0.198 & $\underline{0.471}$ & -0.036 & 0.112 \\
\hline $\begin{array}{l}\text { I prefer to use my smartphone over spending } \\
\text { time with my family or friends }\end{array}$ & 0.200 & 0.024 & $\underline{0.605}$ & -0.068 & 0.140 \\
\hline $\begin{array}{l}\text { My cyber communications with my smartphone are } \\
\text { more frequent than my relationships with my real-life } \\
\text { people }\end{array}$ & 0.123 & 0.108 & $\underline{0.536}$ & 0.196 & 0.107 \\
\hline $\begin{array}{l}\text { I feel that my relationships with my smartphone } \\
\text { friends are more intimate than relationships with my } \\
\text { real-life friends }\end{array}$ & 0.079 & 0.006 & $\underline{0.538}$ & 0.060 & -0.041 \\
\hline $\begin{array}{l}\text { I express my true feelings better via email or SNS } \\
\text { (Line, Twitter, etc.) than by telephone or talking } \\
\text { face-to-face }\end{array}$ & 0.063 & 0.092 & $\underline{0.623}$ & 0.161 & -0.016 \\
\hline $\begin{array}{l}\text { I have a difficult time concentrating in class while } \\
\text { studying due to smartphone use }\end{array}$ & 0.220 & 0.238 & 0.219 & $\underline{0.752}$ & 0.133 \\
\hline $\begin{array}{l}\text { I use my smartphone while studying in class, except } \\
\text { when it is necessary }\end{array}$ & 0.171 & 0.132 & 0.037 & $\underline{0.654}$ & 0.118 \\
\hline
\end{tabular}




\section{Continued}

\begin{tabular}{|c|c|c|c|c|c|}
\hline I have headaches due to excessive smartphone use & -0.034 & 0.116 & 0.110 & 0.154 & $\underline{0.589}$ \\
\hline $\begin{array}{l}\text { My shoulders are stiff due to excessive smartphone } \\
\text { use }\end{array}$ & 0.124 & 0.197 & -0.053 & 0.214 & $\underline{0.678}$ \\
\hline $\begin{array}{l}\text { I feel pain in the wrists or back of the neck when using } \\
\text { a smartphone }\end{array}$ & 0.150 & 0.083 & 0.175 & -0.082 & $\underline{0.603}$ \\
\hline
\end{tabular}

${ }^{\mathrm{a}}$ FC1, FC2, FC3, FC4, and FC5 represent the first, second, third, fourth, and fifth factors, respectively. The eigenvalues were 9.0, 2.2, 1.9, 1.6, and 1.4, respectively, and the cumulative proportions up to the first, second, third, fourth, and fifth factors were $0.31,0.39,0.45,0.51$, and 0.56 , respectively.

Table 2. Mean score for Japanese version of Smartphone Dependence Scale (J-SDS), and mean hours of smartphone use during weekdays and holidays, including Spearman's correlation coefficient values for comparison between J-SDS score and hours of smartphone use.

\begin{tabular}{cccc}
\hline & Mean \pm SD & Correlation coefficient & p value \\
\hline J-SDS & $32.6 \pm 12.5$ & & $<0.001$ \\
Hours of use during weekdays & $3.1 \pm 1.8$ & 0.33 & $<0.001$ \\
\hline Hours of use during holidays & $4.1 \pm 2.1$ & 0.31 & \\
\hline
\end{tabular}

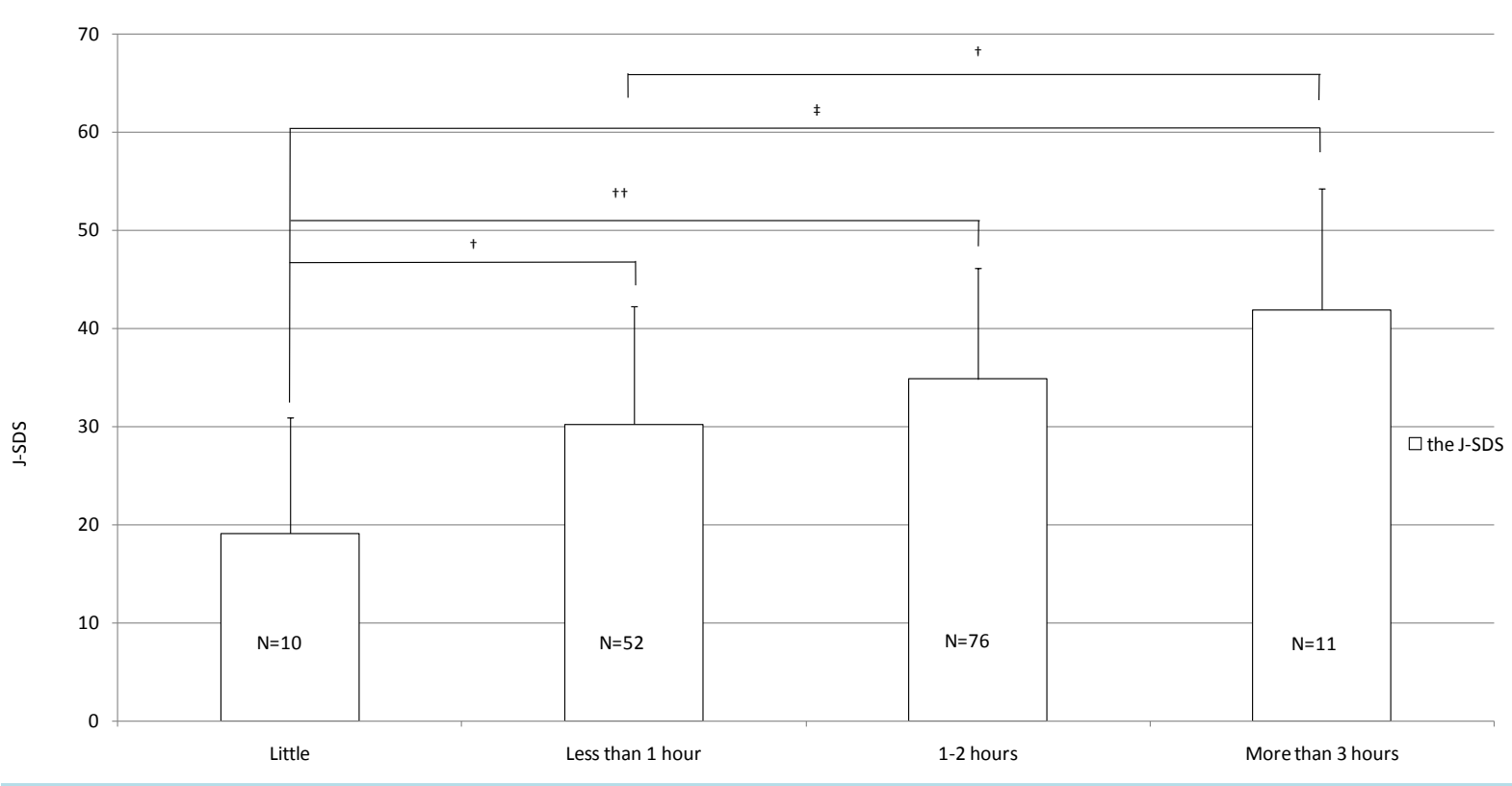

Figure 1. Relationship of hours of smartphone use from 10 p.m. to 4 a.m. with J-SDS score in 149 university students; $†$ : $p<$ $0.05, \dagger+p<0.005, \ddagger: \mathrm{p}<0.001$ (Bonferroni’s multiple comparison test).

It has been reported that exposure to mobile phone emissions at nighttime may have an effect on melatoninonset time [15], while mobile phone use has also been shown to be associated with sleep problems [16] [17]. Munezawa et al. reported that the use of mobile phones for calling and sending text messages after turning off the lights at night was associated with sleep disturbance in Japanese adolescents [17]. They concluded that since many adolescents frequently use a mobile phone at midnight despite the possible adverse effects on sleep, this lifestyle habit should be carefully considered when formulating preventive strategies against sleep disturbance in that age group. Along that line, we think that the J-SDS score can be a useful index of the adverse effects of smartphone use on sleep, because our results were found to be significantly associated with hours of smartphone use late at night and while in bed.

Our study has some limitations. In order to examine the concurrent validity of the J-SDS, we examined the relationship of J-SDS score with hours of smartphone use. However, it will also be necessary to compare that with other standardized scales of smartphone dependence. Furthermore, all of the present results were self- 


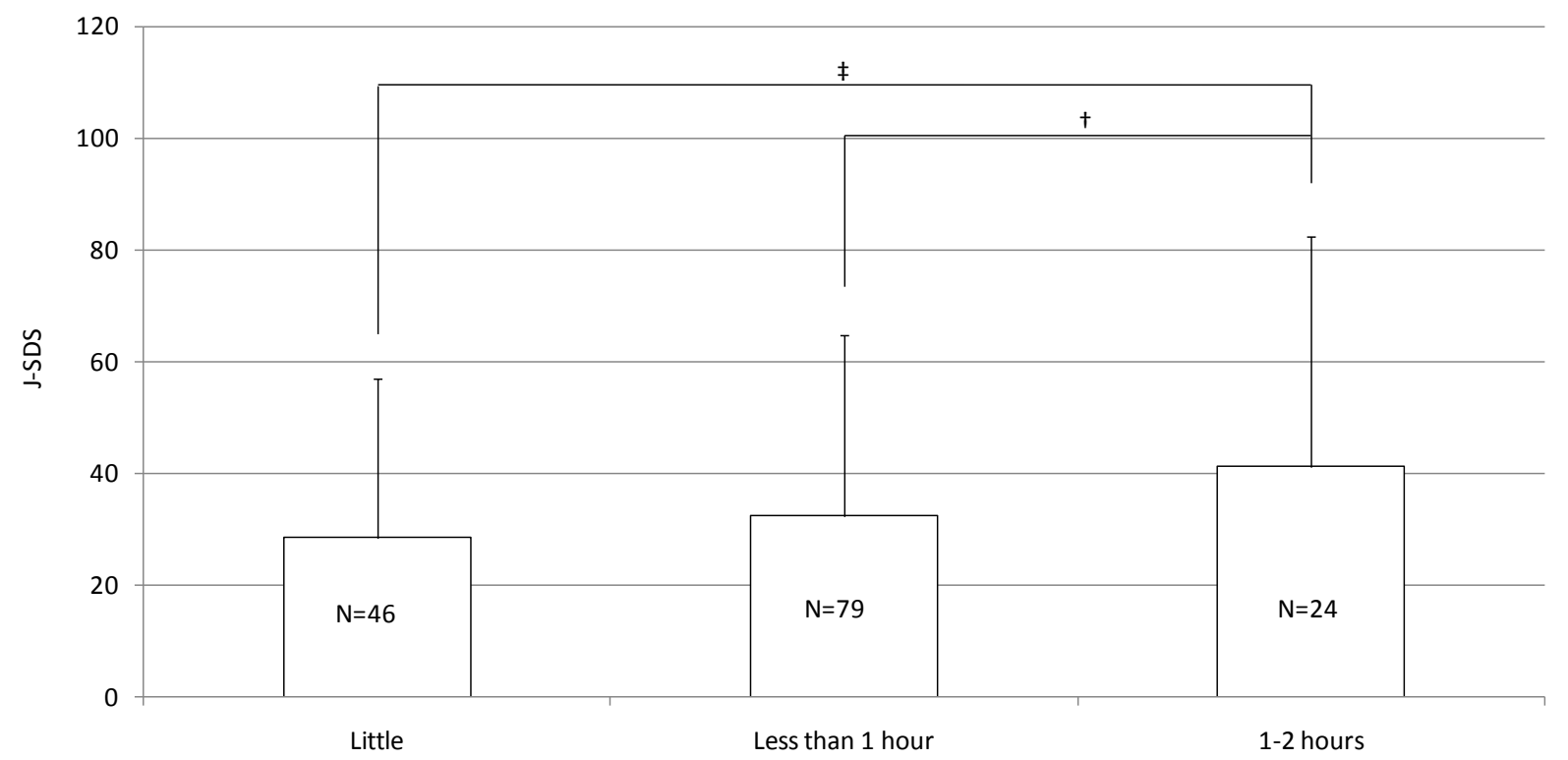

Figure 2. Relationship of hours of smartphone use while in bed with J-SDS score in 149 university students; $\uparrow: p<0.01$, $\ddagger$ : $p$ $<0.001$ (Bonferroni's multiple comparison test).

reported and a more objective method is required to better examine concurrent validity. In addition, the subjects were comprised of students from only two universities, the sample size was too small, and the demographic factor was not fully controlled because the gender ratio was not 1:1. As a result, the present sample group is difficult to generalize, and additional examinations with larger and more varied populations are required in order to evaluate the validity and reliability of this scale.

\section{Conclusion}

In summary, our findings suggest that the J-SDS is a valid and reliable self-administered instrument for screening university students who are at risk of developing smartphone dependence.

\section{Acknowledgements}

This study was supported by a JSPS KAKENHI Grant-in-Aid for Scientific Research (C) (No. 15K01682).

\section{References}

[1] http://www.soumu.go.jp/johotsusintokei/statistics/statistics 05.html

[2] Kwon, M., Kim, D.J., Cho, H. and Yang, S. (2013) The Smartphone Addiction Scale: Development and Validation of a Short Version for Adolescents. PLoS One, 8, e83558. http://dx.doi.org/10.1371/journal.pone.0083558

[3] Choi, H.S., Lee, H.K. and Ha, J. (2012) The Influence of Smartphone Addiction on Mental Health, Campus Life and Personal Relations-Focusing on K University Students. Journal of Korean Data \& Information Science Society, 235, 1005-1015. http://dx.doi.org/10.7465/jkdi.2012.23.5.1005

[4] Kim, N.S. and Lee, K.E. (2012) Effects of Self-Control and Life Stress on Smart Phone Addiction of University Students. Journal of the Korea Society of Health Informatics and Statistics, 372, 72-83.

[5] Kim, D.I, Lee, Y.H, Lee, J.Y., Kim, Y.C., Keum, C.M., et al. (2012) New Patterns in Media Addiction: Is Smartphone a Substitute or a Complement to the Internet? The Korean Journal of Youth Counseling, 201, 71-88.

[6] Young, K.S. (1998) Caught in the Net. John Wiley \& Sons, New York.

[7] Mok, J.Y., Choi. S.W., Kim, D.J., Choi, J.S., Lee, J., Ahn, H., Choi, E.J. and Song, W.Y. (2014) Latent Class Analysis on Internet and Smartphone Addiction in College Students. Neuropsychiatric Disease and Treatment, 10, 817-828.

[8] Ching, S.M., Yee, A., Ramachandran, V, Lim, S.M.S., Sulaiman, W.A.W., Foo, Y.L. and Hoo, F.H. (2015) Validation of a Malay Version of the Smartphone Addiction Scale among Medical Students in Malaysia. PLoS One, 10, e0139337. http://dx.doi.org/10.1371/journal.pone.0139337 
[9] Kim, D., Lee, Y., Lee, J., Nam, J.K. and Chung, Y. (2014) Development of Korean Smartphone Addiction Proneness Scale for Youth. PLoS One, 9, e97920. http://dx.doi.org/10.1371/journal.pone.0097920

[10] Lin, Y.H., Chang, L.R., Lee, Y.H., Tseng, H.W., Kuo, T.B.J. and Chen, S.H. (2014) Development and Validation of the Smartphone Addiction Inventory (SPAI). PLoS One, 9, e98312. http://dx.doi.org/10.1371/journal.pone.0098312

[11] Kwon, M., Lee, J.Y., Won, W.Y., Park, J.W., Min, J.A., Hahn, C., et al. (2013) Development and Validation of a Smartphone Addiction Scale (SAS). PLos One, 8, e56936. http://dx.doi.org/10.1371/journal.pone.0056936

[12] Toda, M., Monden, K., Kubo, K. and Morimoto, K. (2004) Cellular Phone Dependence Tendency of Female University Students. Japanese Journal of Hygiene, 59, 383-386. http://dx.doi.org/10.1265/jjh.59.383

[13] Toda, M., Nishio, N. and Takeshita, T. (2015) Development of a New Scale for Gauging Smartphone Dependence. Japanese Journal of Hygiene, 70, 259-263. http://dx.doi.org/10.1265/jjh.70.259

[14] IBM SPSS Statistics 19 (2010) SPSS Inc.

[15] Wood, A.W., Loughran, S.P. and Stough, C. (2006) Does Evening Exposure to Mobile Phone Radiation Affect Subsequent Melatonin Production? International Journal of Radiation Biology, 82, 69-76. http://dx.doi.org/10.1080/09553000600599775

[16] Loughran, S.P., Wood, A.W., Barton, J.M., et al. (2005) The Effect of Electromagnetic Fields Emitted by Mobile Phones on Human Sleep. Neuroreport, 16, 1973-1976. http://dx.doi.org/10.1097/01.wnr.0000186593.79705.3c

[17] Munezawa, T., Kaneita, Y., Osaki, Y., et al. (2011) The Association between Use of Mobile Phones after Lights Out and Sleep Disturbances among Japanese Adolescents: A nationwide Cross-Sectional Survey. Sleep, 34, 1013-1020. http://dx.doi.org/10.5665/sleep.1152

\section{Submit or recommend next manuscript to SCIRP and we will provide best service for you:}

Accepting pre-submission inquiries through Email, Facebook, LinkedIn, Twitter, etc.

A wide selection of journals (inclusive of 9 subjects, more than 200 journals)

Providing 24-hour high-quality service

User-friendly online submission system

Fair and swift peer-review system

Efficient typesetting and proofreading procedure

Display of the result of downloads and visits, as well as the number of cited articles

Maximum dissemination of your research work

Submit your manuscript at: http://papersubmission.scirp.org/ 